\title{
Opioid-Induced Constipation
}

National Cancer Institute

\section{Source}

National Cancer Institute. Opioid-Induced Constipation. NCI Thesaurus. Code C148034.

Constipation that results from, or follows, treatment with an opioid or opioid-containing medication. 